Int. J. Dev. Biol. 48: 645-653 (2004)

doi: $10.1387 / \mathrm{ijdb} .041816 \mathrm{fl}$

Original Article

\title{
Expression and activity of osteoblast-targeted Cre recombinase transgenes in murine skeletal tissues
}

\author{
FEI LIU1 ${ }^{1}$, HENNING W. WOITGE ${ }^{1}$, ALEN BRAUT ${ }^{2}$, MARK S. KRONENBERG ${ }^{3}$, ALEXANDER C. LICHTLER ${ }^{3}$, \\ MINA MINA ${ }^{2}$ and BARBARA E. KREAM*,1,3 \\ Departments of Medicine ${ }^{1}$, Pediatric Dentistry ${ }^{2}$ and Genetics and Developmental Biology ${ }^{3}$, University of Connecticut Health Center, \\ Farmington, Connecticut, USA
}

\begin{abstract}
The Cre/loxP recombination system can be used to circumvent many of the limitations of generalized gene ablation in mice. Here we present the development and characterization of transgenic mice in which Cre recombinase has been targeted to cells of the osteoblast lineage with $2.3 \mathrm{~kb}$ (Col 2.3-Cre) and $3.6 \mathrm{~kb}$ (Col 3.6-Cre) fragments of the rat Col1a1 promoter. Cre mRNA was detected in calvaria and long bone of adult Col 2.3-Cre and Col 3.6-Cre mice, as well as in tendon and skin of Col 3.6-Cre mice. To obtain a historical marking of the temporal and spatial pattern of Cre-mediated gene rearrangement, Col-Cre mice were bred with ROSA26 (R26R) mice in which Cremediated excision of a floxed cassette results in LacZ expression. In Col 2.3-Cre;R26R and Col 3.6Cre;R26R progeny, calvarial and long bone osteoblasts showed intense $\beta$-gal staining at embryonic day 18 and postnatal day 5 . The spatial pattern of $\beta$-gal staining was more restricted in bone and in bone marrow stromal cultures established from Col 2.3-Cre;R26R mice. Similar differences in the spatial patterns of expression were seen in transgenic bone carrying Col1a1-GFP visual reporters. Our data suggest that Col 2.3-Cre and Col 3.6-Cre transgenic mice may be useful for conditional gene targeting in vivo or for obtaining osteoblast populations for in vitro culture in which a gene of interest has been inactivated.
\end{abstract}

KEY WORDS: Cre recombinase, Col1a1 promoter, osteoblast, transgenic mouse, Cre/loxP

\section{Introduction}

Targeting a gene deletion to a tissue or cell type of interest using the Cre/loxP recombination system can circumvent many limitations of global gene knockout models such as perinatal lethality and infertility. (Karaplis and Kronenberg 1996). The P1 bacteriophage enzyme Cre recombinase catalyzes the rearrangement of DNA fragments flanked by two 34 bp loxP sites (floxed) (Sauer and Henderson 1988, Sauer 1993). Conditional gene targeting using the Cre/loxP system requires several considerations (Nagy 2000). The promoter driving the Cre recombinase should contain the appropriate regulatory elements to confer tissue-specific expression and Cre recombinase must be expressed at a sufficient level to enable efficient recombination of the floxed gene of interest. The development of Cre transgenic mice has facilitated the tissuespecific ablation of floxed genes in vivo (Kulkarni et al., 1999, Sjogren et al., 1999, Tronche et al., 1999, Yakar et al., 1999, Guo et al., 2000, Li et al., 2000, Liu et al., 2000).

Conditional gene knockouts in osteoblasts have been accomplished with the osteocalcinpromoter, which is expressed very late in embryogenesis in the mouse and highly restricted to differentiated osteoblasts (Ducy et al., 1996, Hoffmann et al., 1996). Cre recombinase expression directed with a $3.5 \mathrm{~kb}$ human osteocalcin promoter has been used successfully to inactivate expression of the IGF-I receptor in mature osteoblasts (Zhang et al., 2002). Promoter strength is important since a $1.7 \mathrm{~kb}$ murine osteocalcin promoter did not drive Cre expression at a level sufficient to induce gene rearrangement in mature osteoblasts (Dacquin et al., 2002). Since the osteocalcinpromoter is first activated in fetal life just prior to birth (Frenkel et al., 1997, Quarles et al., 1997), it would not suitable for inactivating a gene during early development.

The $\alpha 1(\mathrm{I})$ collagen promoter (Col1a I), which is expressed earlier during skeletal development than the osteocalcinpromoter, can be used to target cells of the osteoblast lineage. A $2.3 \mathrm{~kb}$ murine Col1a1 promoter has been used to drive Cre recombinase expression specifically in osteoblasts (Dacquin et al., 2002). A rat $3.6 \mathrm{~kb}$ Col1a1 promoter (Col3.6) drives reporter gene expression

Abbreviations used in this paper: GFP, green fluorescent protein; R26R, ROSA26.

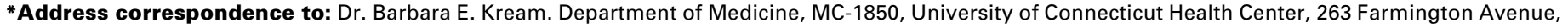
Farmington, CT 06030, Connecticut, USA. Fax: +1-860-679-1258. email: kream@nso1.uchc.edu
} 

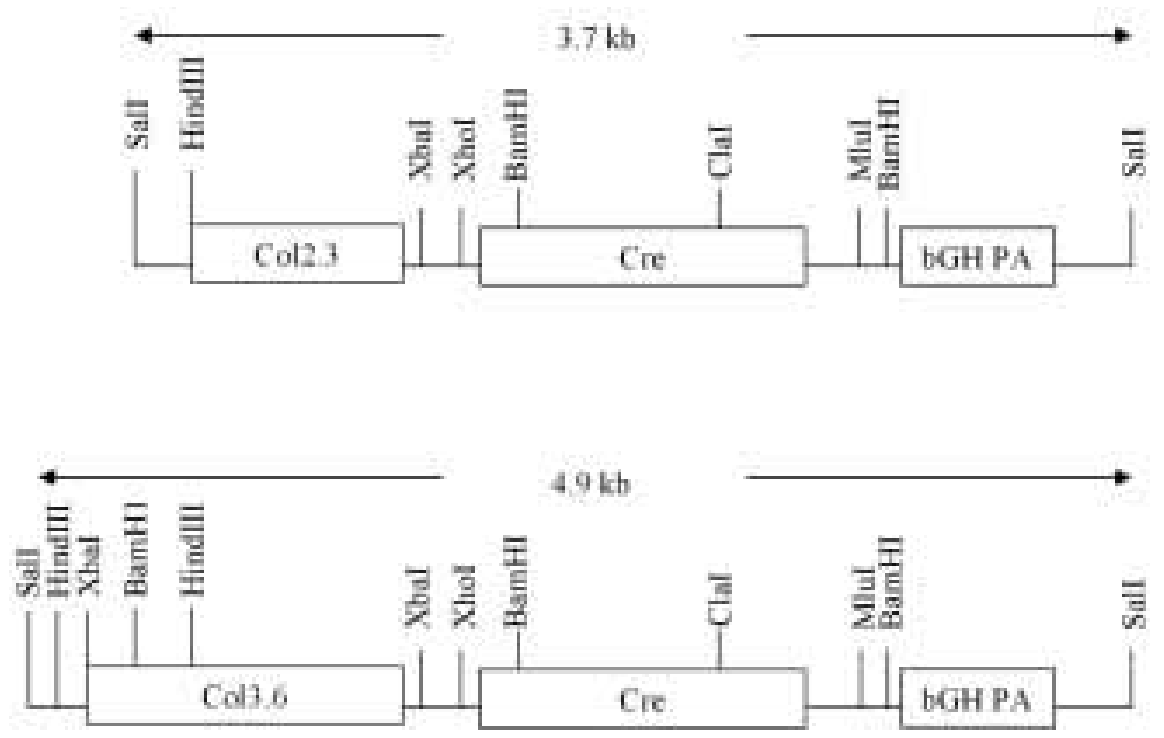

Fig. 1. Col1a1-Cre expression plasmids. Cloning of $\mathrm{Col}$ 2.3-Cre and Col 3.6-Cre expression plasmids in $\mathrm{pBC}$ SK+/- plasmid was performed as described in Materials and Methods.

\section{Results}

Cre recombinase is expressed in osseous tissues of Col 2.3-Cre and Col 3.6-Cre transgenic mice

To achieve osteoblast-directed gene expression using the Cre/loxP system, we generated Col 2.3-Cre and Col 3.6-Cre transgenes in which Cre recombinase was cloned downstream of either a $2.3 \mathrm{~kb}$ or a $3.6 \mathrm{~kb}$ fragment, respectively, of the rat Col1a1 promoter (Fig. 1). Multiple transgenic lines were produced carrying Col 2.3Cre and Col 3.6-Cre. Hemizygous Col-Cre mice were healthy and fertile and several lines have been bred to homozygosity. When bred with wild type mice, both males and females transmitted the transgene in the expected Mendelian ratios. To examine Cre expression in vivo, RNA extracted from tissues of 6-week-old mice were subjected to Northern blot analysis. Cre mRNA was highly expressed in long bones and calvaria of Col 2.3-Cre and Col 3.6-Cre transgenic mice, as well as in tendon in Col 3.6-Cre transgenic in transgenic mice in both osseous and non-osseous tissues, whereas a truncated rat $\mathrm{Col} 2.3 \mathrm{~kb}$ promoter (Col2.3) shows a more restricted pattern of expression, with strong activity in bone, low activity in tendon and very low or undetectable activity in other tissues (Pavlin et al., 1992, Bogdanovic et al., 1994, Kalajzic et al., 2002). Ex vivo analysis of bone marrow stromal cell and primary calvarial osteoblast cultures show that the Col 3.6 promoter is expressed early during osteogenic differentiation, whereas the Col 2.3 promoter is activated later and its activity is restricted to maturing osteoblasts (Kalajzic et al., 2002).

The goal of the present study was to generate and characterize transgenic mice with osteoblast-directed Cre expression for conditional gene knockouts in bone. A Cre cDNA was cloned downstream of the Col 2.3 and Col 3.6 promoter fragments to produce Col 2.3-Cre and Col 3.6-Cre transgenes, respectively. Transgenic mice were generated carrying the Col 2.3-Cre and Col 3.6-Cre transgenes. To provide a historical marking of the temporal and spatial pattern of Cre activity, Col-Cre mice were bred with Cre indicator mice in which the ubiquitously expressed endogenous ROSA26 locus was engineered with a targeting construct (R26R) containing a LacZ gene downstream of a floxed cassette containing the PGK promoter, a neo cDNA and three polyadenylation signals (Soriano 1999); $\beta$ galactosidase ( $\beta$-gal) is expressed following Cre-mediated excision of the floxed cassette. We found that both the Col 2.3-Cre and Col 3.6-Cre transgenes drove sufficient Cre expression to rearrange the floxed ROSA26 locus in osteoblasts. In calvaria, the Col 2.3 promoter was expressed in mature osteoblasts but not in suture mesenchyme, whereas the Col 3.6 promoter was expressed broadly in cells of the osteoblast lineage and in suture mesenchyme. We also compared the historical pattern of Cre activity with real time Col 2.3- and Col 3.6-driven GFP transgenes. With both upstream promoters, the spatial pattern of GFP expression in bone was similar but not identical to the recombination pattern observed with the respective Col-Cre transgenes. mice (Fig. 2). There was no detectable Cre mRNA expression in skin. In all other tissues tested including brain, kidney, liver and lung, a faint Cre mRNA transcript was detected if the Northern blot was overexposed to film. Thus, Cre mRNA was selectively and highly expressed in transgenic bone, although it was also expressed at a very low level in other tissues.

\section{Col 2.3-Cre and Col 3.6-Cre transgenes cause gene rearrange- ment in bone}

To examine the pattern of Cre-mediated gene rearrangement in vivo, hemizygous Col 2.3-Cre and Col 3.6-Cre mice were bred with heterozygous Cre indicator mice in which the endogenous

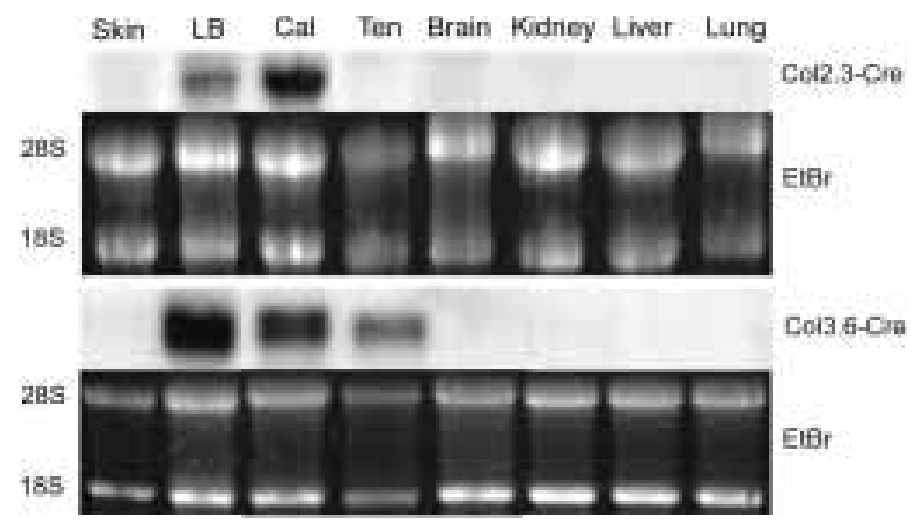

Fig. 2. Expression of $\mathrm{Col}$ 2.3-Cre and $\mathrm{Col}$ 3.6-Cre in tissues from 6 week-old mice. Expression of Col 2.3-Cre and Col 3.6-Cre transgene was detected by Northern blotting in skin, long bone (LB), calvaria (Cal), tendon (Ten), brain, kidney, liver and lung. Both Col 2.3-Cre and Col 3.6-Cre transgene were expressed in long bone and calvaria. Col3.6-Cre transgene was also detected in tendon. However, very low levels of Col 2.3-Cre transgene expression in tendon, brain, kidney, liver and lung and Col 3.6Cre transgene expression in brain, kidney, liver and lung could be detected by overexposing the film. 

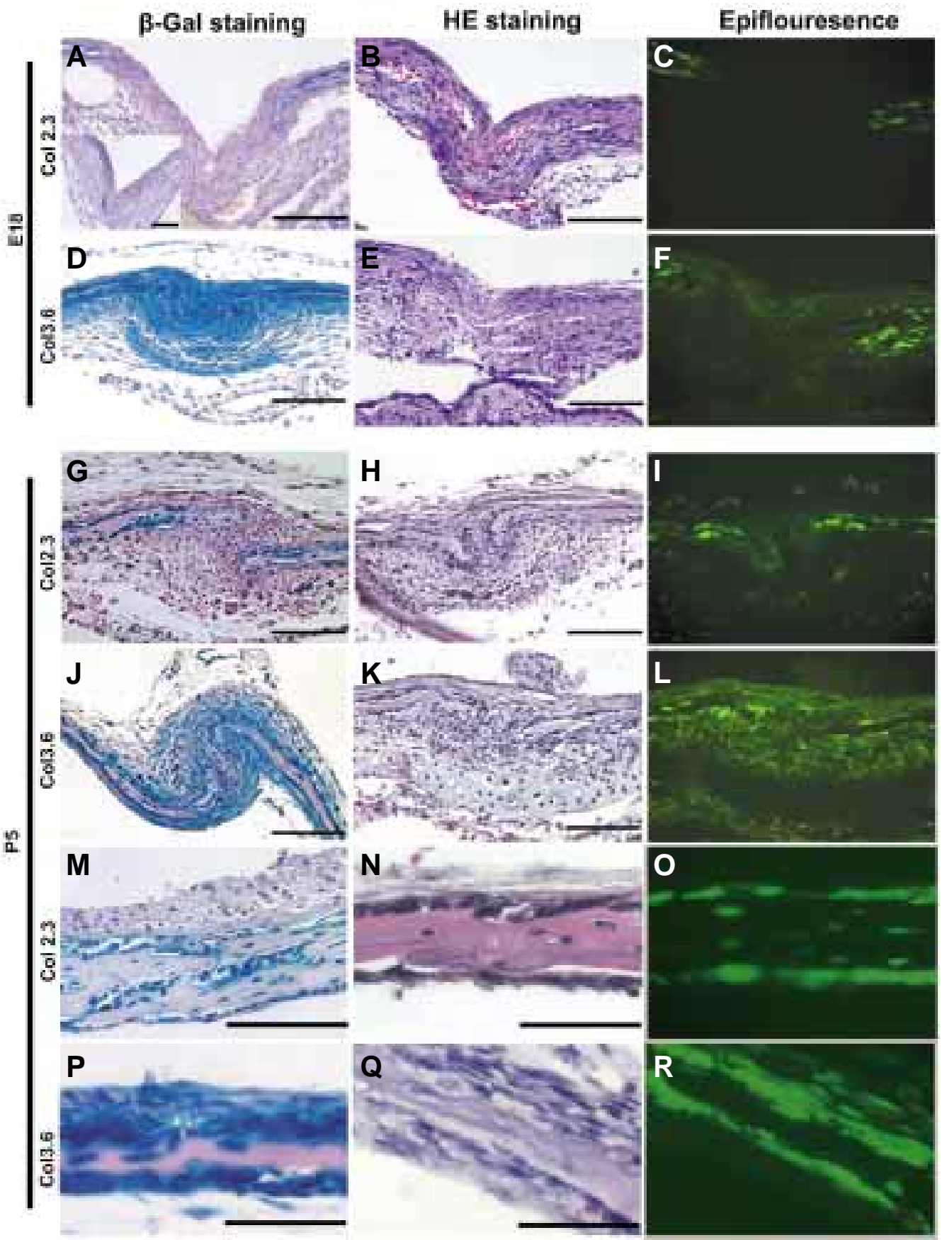

Fig. 3. $\beta$-galactosidase and GFP expression in sagittal sutures and parietal bones of Col-Cre;R26R and pOBCol-GFP mice. Frontal sections of calvaria of Col 2.3-Cre/R26R (A, G,M), pOBCol 2.3-GFP $(C, I, O), C o l$ 3.6Cre;R26R (D,J,P) and pOBCol 3.6-GFP $(F, L, R)$ mice at $E 18(A-F)$ and $P 5(G-R)$. Calvaria of $\mathrm{Col}$ 2.3-Cre:R26R and $\mathrm{Col}$ 3.6-Cre;R26R mice were stained for $\beta$ gal activity and paraffin sections were counterstained with hematoxylin. Paraffin sections of $\mathrm{pOBCol}$ 2.3-GFP and pOBCol 3.6-GFP bones were counterstained with hematoxylin and eosin. Epifluorescence signals were visualized using a Nikon E600 microscope. (A,D) Frontal sections through the sagittal sutures of $\mathrm{Col} 2.3-\mathrm{Cre} ; R 26 \mathrm{R}$ and Col 3.6-Cre;R26R E18 calvaria. (A) Stained cells were observed in osteoblasts and osteocytes of the two approximating Col 2.3-Cre; R26R parietal bones. Note that there was no staining in the sutures. The insert is the Crenegative;R26R parietal bone. (D) Stained cells were observed in osteoblasts and osteocytes of the two approximating Col 3.6-Cre;R26R parietal bones and in the sutures. (B, C,E, $\mathbf{F})$ Frontal sections through the sagittal sutures of $\mathrm{POBCol}$ 2.3-GFP and $\mathrm{DOBCol}$ 3.6-GFP E18 calvaria. (B,C) (B) is the histological view of (C). GFP fluorescence was seen in osteoblasts and osteocytes of the two approximating pOBCol2.3-GFP parietal bones but not in the sutures. (E,F) (E) is the histological view of (F). In addition to the strong GFP fluorescence in osteoblasts and osteocytes, a low but detectable level of GFP fluorescence was seen in the suture mesenchyme of pOBCol 3.6GFP calvaria. (G,J) Frontal sections through the sagittal sutures of Col 2.3-Cre;R26R and Col 3.6-Cre;R26R P5 calvaria. (G) Stained cells were observed in osteoblasts and osteocytes of the two approximating Col 2.3-Cre;R26R parietal bones but not in the sutures. (J) Stained cells were observed in both osteoblasts and osteocytes of the two approximating Col 3.6-Cre;R26R parietal bones and in the sutures. $(\mathbf{H}, \mathbf{I}, \mathbf{K}, \mathbf{L})$ Frontal sections through the sagittal sutures of pOBCol 2.3-GFP and pOBCol 3.6-GFP P5 calvaria. (H, I) (H) is the histological view of (I). GFP fluorescence was seen in osteoblasts and osteocytes of the two approximating pOBCol 2.3-GFP parietal bones but not in the sutures. (K, L) (K) is the histological view of (L). GFP fluorescence was seen in osteoblasts, osteocytes and cells within the suture mesenchyme pOBCol 3.6-GFP of bones. (M,P) Frontal sections through parietal bones of Col 2.3-Cre;R26R and Col 3.6-Cre;R26R P5 calvaria. (M) Stained cells were seen in osteoblasts and osteocytes but not in the fibroblastic layer of the periosteum of Col 2.3-Cre;R26R parietal bones. (P) Stained cells were seen in osteoblasts, osteocytes and the fibroblastic layer of the periosteum of Col 3.6-Cre;R26R bones. (N,0,0,R) Frontal sections through the parietal bones of pOBCol 2.3-GFP and pOBCol 3.6-GFP P5 calvaria. (N,0) (N) is the histological view of (O). GFP fluorescence was seen in the innermost osteoblast layer and in osteocytes of pOBCol 2.3-GFP parietal bones. (Q, R) (Q) is the histological view of (R). GFP fluorescence was seen in the osteoblast layer, in osteocytes and in the fibroblastic layer of the periosteum in pOBCol 3.6-GFP parietal bones. Scale bars in all pictures, $100 \mu \mathrm{m}$. 

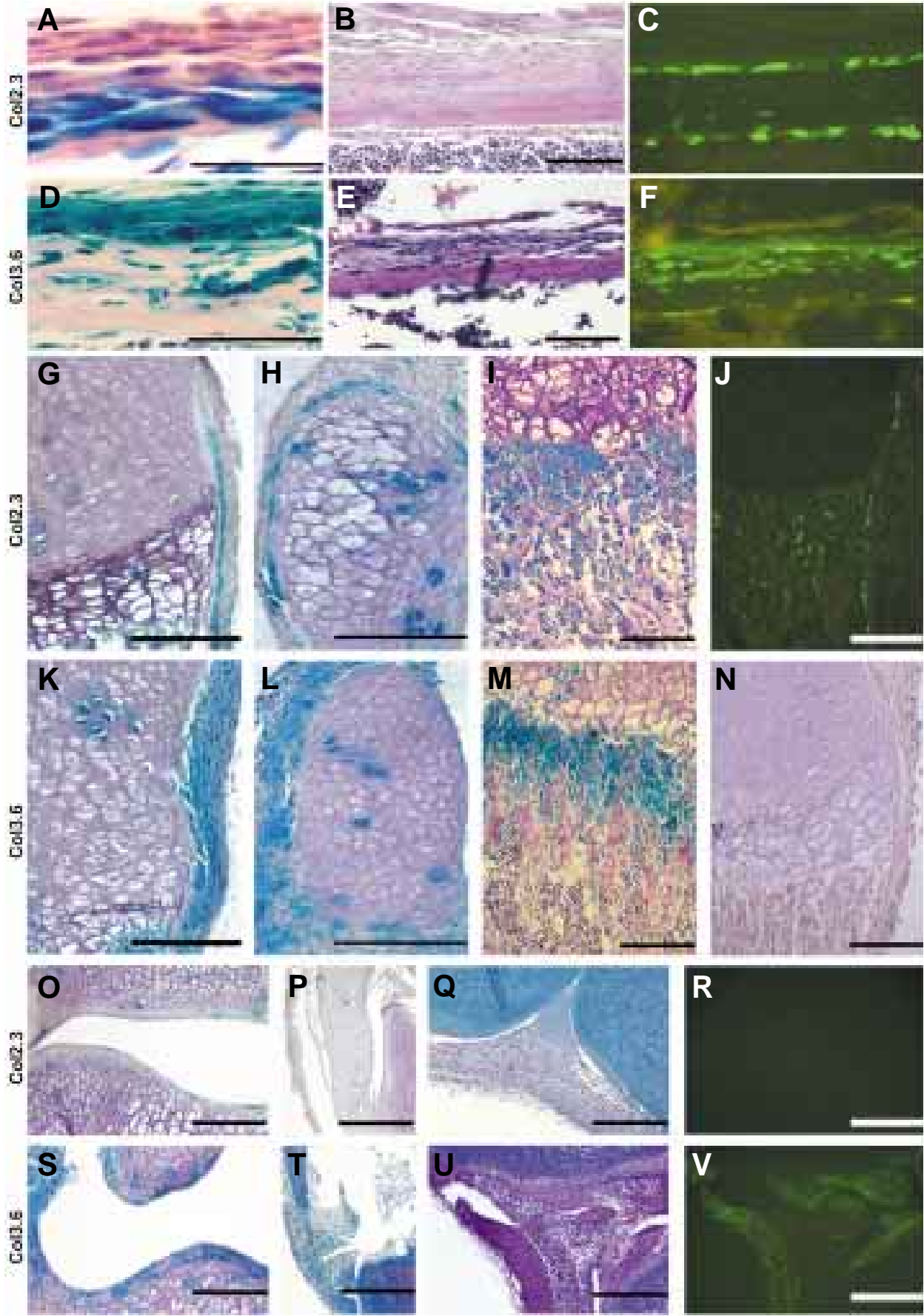
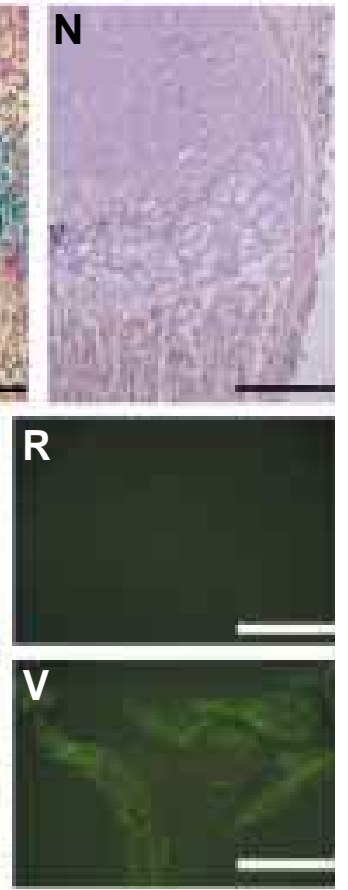

Fig. 4. $\beta$-galactosidase and GFP expression in long bones of Col-Cre;R26R and pOBCol-GFP mice. Longitudinal sections through the tibia, femur and foot of P5 Col 2.3-Cre;R26R (A, G, H,I,O,P) and Col 3.6Cre;R26R (D, K, L, $\mathbf{M}, \mathbf{S}, \mathbf{T})$ mice and through the tibia of E18 pOBCol 2.3-GFP (C,R) and pOBCol3.6-GFP(F,J,V) mice. Bones of Col 2.3-Cre;R26R and Col 3.6-Cre;R26R mice were stained for $\beta$-gal activity and paraffin sections were counterstained with hematoxylin. Paraffin sections of $\mathrm{POBCol}$ 2.3GFP and pOBCol3.6-GFP bones were counterstained with hematoxylin and eosin Epifluorescence signals were visualized using a Nikon E600 microscope. (A,D) Longitudinal sections through the femur of $P 5$ Col 2.3-Cre;R26R and Col 3.6-Cre;R26R mice. (A) Stained cells were observed in osteocytes and in the osteoblast layer of the periosteum, but not in the fibroblastic layer of the periosteum of Col2.3-Cre;R26R bone. (D) Stained cells were observed in osteoblasts, osteocytes and the fibroblastic layer of the periosteum in Col 3.6Cre;R26R bone. (B,C,E,F) Longitudinal sections through the femur of $P 5 \mathrm{POBCol}$ 2.3GFP and $p O B C o$ l 3.6-GFP mice. (B,C) $(B)$ is the histological view of (C). High levels of GFP fluorescence were seen in the osteoblastic layer of the periosteum of the femur, but not in the fibroblastic layer of the periosteum of $\mathrm{OBCOl}$ 2.3-GFP bones. (E,F) $(E)$ is the histological view of (F). GFP fluorescence was seen in the fibroblastic layers of the periosteum of pOBCol 3.6-GFP bones. $(\mathbf{G}, \mathbf{K})$ Longitudinal sections through the femoral growth plate of P5 $\mathrm{Col}$ 2.3Cre:R26R (G) and Col3.6-Cre;R26R (K) mice. (G) In the periosteum surrounding the growth plate, only the innermost layer of cells were stained. There were no stained cells in the periochondrium. Clusters of stained chondrocytes were occasionally seen in the proliferative and hypertrophic zones. (K) The entire periosteum and perichondrium were stained. Clusters of stained chondrocytes were occasionally seen in the proliferative and hypertrophic zones. $(\mathbf{H}, \mathbf{L})$ Cross sections of the foot bone of P5 Col 2.3-Cre; R26R (H) and Col 3.6-Cre;R26R (L) mice. (H) During endochondral bone formation, the innermost layer of perichondrial cells close to the hypertrophic chondrocytes were stained. No stained cells were seen in the outer layer of the perichondrium. Clusters of chondrocytes were stained. (K) The entire perichondrium was stained. Stained cells also were observed in clusters of chondrocytes. (I,M, $\mathbf{N}, \mathbf{J})$ Longitudinal sections through the femur of P5 Col 2.3-Cre;R26R (I), Col 3.6-Cre;R26R (M) and Cre-negative;R26R (N) mice and E18 pOBCol 3.6-GFP (J) mice. (I,M) Trabecular osteoblasts were stained in both Col 2.3-Cre;R26R and Col 3.6-Cre;R26R femurs. There were some stained cells at the junction between the hypertrophic zone and the primary spongiosa. (N) Stained cells were not seen in Cre-negative;R26R femurs. (J) GFP fluorescence was seen in trabecular bone and periosteum, but not in growth plate of $\mathrm{OB}$ Col2.3-GFP bones. (O,P,S,T) Longitudinal sections through the articulating heel joint of P5 Col 2.3-Cre; $R 26 R$ (O,P) and Col3.6-Cre;R26R (S,T) mice. (O,S) Stained chondrocytes were occasionally seen in both Col 2.3-Cre;R26R and Col 3.6-Cre;R26R joints, with more stained cells in Col 3.6-Cre;R26R joints. (P) The heel ligament was not stained in Col 2.3-Cre;R26R mice. (T) The entire heel ligament was stained in Col 3.6-Cre;R26R mice. (Q, R,U,V) Longitudinal sections through the articulating knee joint of E18 pOBCol 2.3-GFP (Q,R) and pOBCol 3.6-GFP (U,V) mice. $(\mathbf{Q}, \mathbf{R})(Q)$ is the histological view of (R). GFP fluorescence was not seen in patellar cells and the ACL ligament of $p O B C o l$ 2.3-GFP mice. (U,V) $(U)$ is the histological view of (V). Most cells in the patellar region and ACL ligament were stained. Scale bars in all pictures, $100 \mu m$. 
ROSA26 locus has been targeted with a construct (R26R) consisting of the LacZ gene downstream of a lox P-flanked sequence containing a neo expression cassette and three polyadenylation signals (Soriano 1999). Following Cre-mediated excision of the floxed cassette, R26R reporter mice express LacZ, which can be monitored by $\beta$-gal staining.

In calvaria of Col 2.3-Cre;R26R mice, all osteoblasts and osteocytes were stained, whereas the other cells of the inner and outer periosteum and the suture mesenchyme were negative for LacZ (Fig. 3 A,G,M). The staining pattern was similar between E18 (Fig. 3A) and P5 (Fig. 3G) animals. In calvaria of Col 3.6Cre;R26R mice, in addition to the strong staining in osteoblasts and osteocytes, preosteoblasts located adjacent to the mature osteoblasts, the outer fibrous layer of periosteum and suture mesenchyme were stained (Fig. $3 \mathrm{D}, J, P$ ). This latter staining pattern was similar between E18 (Fig. 3D) and P5 (Fig. 3J) animals. To better understand the difference in recombination pattern between Col 2.3-Cre;R26R mice and Col 3.6-Cre;R26R mice, the pattern of GFP reporter expression was examined in calvaria from E18 and P5 pOBCol2.3-GFP (Fig. 3 C,I,O) and pOBCol3.6-GFP (Fig. 3 F,L,R) mice. In pOBCol2.3-GFP mice, GFP fluorescence was observed in osteoblasts and osteocytes but not in the suture mesenchyme nor in the preosteoblasts and the fibrous layers of the inner and outer periosteum. However, in pOBCol3.6-GFP mice, GFP fluorescence was observed in all of the aforementioned cells and regions. In summary, similar to the $\beta$-gal staining pattern observed in Col-Cre;R26R mice, we observed a more restricted GFP expression in pOBCol2.3-GFP at both $\mathrm{E} 18$ and P5.

In long bone of Col 2.3-Cre;R26R mice, all osteoblasts and osteocytes in the cortical and trabecular compartments were stained (Fig. 4 A,G,H,I). Similar to calvaria, the preosteoblasts and the outer fibrous layer of periosteum were not stained. In contrast, Col 3.6-Cre;R26R mice showed a more widespread staining pattern since the entire periosteum was stained (Fig. 4 $\mathrm{D}, \mathrm{K}$ ). Staining was not seen in control sections from R26R (Crenegative) mice (Fig. 4N). Likewise, a more restricted GFP expression pattern was seen in the periosteum of the long bone in pOBCol2.3-GFP (Fig. 4C) compared to pOBCol3.6-GFP mice (Fig. 4F).

During endochondral bone formation, concurrent with chondrocyte hypertrophy in the growth plate, chondrogenic cells in the inner layer of the perichondrium become osteoprogenitor cells that differentiate into osteoblasts, while the overlying perichondrium becomes a periosteum (Ross et al., 2003). This process was clearly evident in hyaline cartilage of Col 2.3-Cre;R26R mice
Fig. 5. $\beta$-galactosidase staining in cultured bone marrow stromal cells derived from Col 2.3Cre;R26R and Col 3.6-Cre;R26R mice. $\beta$-gal staining of bone marrow stromal cells of $\mathrm{Col} 2.3-$ Cre;R26R (A,D,E), Col 3.6Cre; $R 26 R(B, G, H, I)$ and Crenegative; $R 26 R(C, F)$ mice from day $5(A, B, C)$ and day 21 cultures $(D, E, F, G, H, I)$. Bone marrow stromal cells were cultured in alphaMEM with $10 \%$ fetal calf serum. On day 7, the medium was changed to alpha-MEM supplemented with $50 \mu \mathrm{g} / \mathrm{ml}$ ascorbic acid and $8 \mathrm{mM} \beta$-glycerophosphate. Medium was changed every 2 days for the duration of the experiment. Cells were fixed in phosphate buffer ( $\mathrm{pH}$ 7.3) containing $0.2 \%$ gluteraldehyde and stained for $\beta$-gal activity. (A,B,C) Day 5 cultures of bone marrow stromal cells established from $\mathrm{Col}$ 2.3-Cre;R26R (A), Col 3.6Cre;R26R (B) and Crenegative; $R 26 R$ (C) mice. Some stained cells were seen in Col 2.3Cre;R26R and Col 3.6-Cre;R26R cultures, but not in Crenegative; R26R cultures. Stained

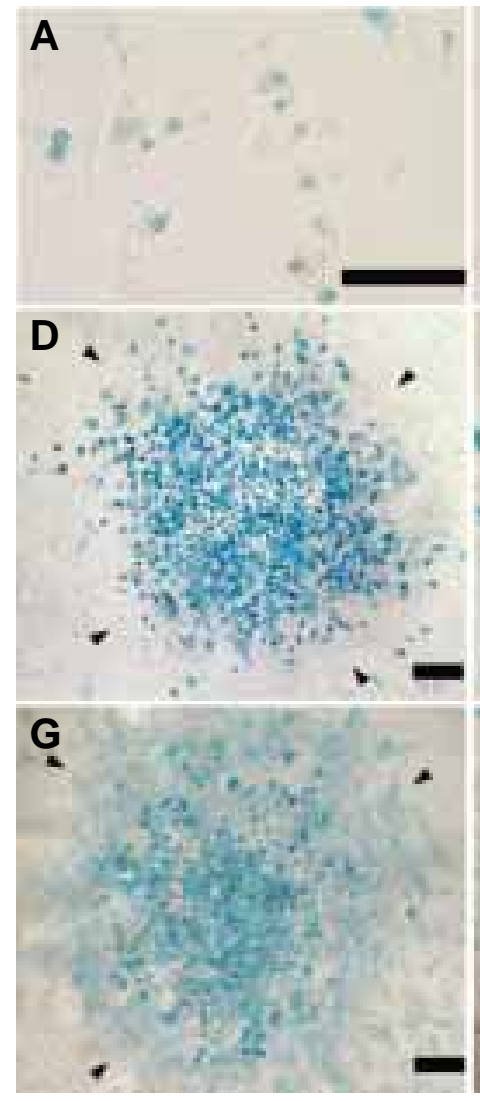

B

C

cells were rounded and there was no colony formation in the cultures. (D, E, F) Day 21 cultures of bone marrow stromal cell established from Col 2.3Cre;R26R (D,E) and Cre-negative;R26R (F) mice. (D) Stained cells were cuboidal and located in the center of colonies. Peripheral cells of the colony were not stained. (E) Stained cell were cuboidal cells and dispersed within the colony. (F) There were no stained cells in the Cre-negative;R26R cultures. (G,H,I) Day 21 cultures of bone marrow stromal cells established from Col 3.6-Cre;R26R mice. (G) Cuboidal cells in the center of the colony showed stronger staining than peripheral cells. (H) Cuboidal cells in the center of the colony showed strong staining. Scale bars in all pictures represent 1 mm. Arrowheads in panels (D-I) indicate the boundary of the colonies. 
in which only the inner most osteoblasts adjacent to the hypertrophic hyaline cartilage were stained (Fig. $4 \mathrm{G}, \mathrm{H}$ ). By contrast, the entire perichondrium in Col 3.6-Cre;R26R mice was stained (Fig. $4 \mathrm{~K}, \mathrm{~L})$. Similar $\beta$-gal staining patterns were observed in trabecular bone in both Col 2.3-Cre;R26R (Figure 4I) and Col 3.6-Cre;R26R (Fig. 4M) mice. Likewise, GFP fluorescence was similar in trabecular bone of pOBCol2.3-GFP (Fig. 4J) and pOBCol3.6-GFP (data not shown) mice at both E18 (Fig. 4J) and P5 (data not shown).

In the articular cartilage of long bone, strong staining was observed in Col 3.6-Cre;R26R mice (Fig. 4S), whereas very few cells were stained in Col 2.3-Cre;R26R mice (Fig. 4O). Sporadic staining was observed in growth plate chondrocytes in both Col 2.3-Cre;R26R (Fig. 4 G,H) and Col 3.6-Cre;R26R (Fig. 4 K,L) mice. Some proliferative chondrocytes (Fig. $4 \mathrm{G}, \mathrm{H}, \mathrm{K}, \mathrm{L}$ ) as well as occasional hypertrophic chondrocytes (Fig. $4 \mathrm{G}, \mathrm{K}$ ) in the area of the future secondary ossification center and cells underneath the articular cartilage (data not shown) were stained. However, in pOBCol2.3-GFP and pOBCol3.6-GFP mice, GFP fluorescence was not seen in articular cartilage or chondrocytes (Fig. 4J, data not shown).

Strong expression of Cre mRNA was observed in tendon of Col 3.6-Cre mice but only very weak expression in tendon of Col 2.3Cre mice (Fig. 1). Likewise, tendon of Col 3.6-Cre;R26R mice was strongly stained (Fig. 4T), whereas tendon of Col 2.3-Cre;R26R mice was not stained (Fig. 4P). Interestingly, GFP fluorescence was observed in the knee ligament in pOBCol3.6-GFP mice (Fig. $4 \mathrm{~V}$ ) but not in pOBCol2.3-GFP mice (Fig. 4R).

\section{Col 2.3-Cre mediates more specific osteoblast-directed re- combination in vitro than Col 3.6-Cre}

To better appreciate the temporal pattern of Cre-mediated gene rearrangement in osteoblasts ex vivo, bone marrow stromal cells from Col 2.3-Cre;R26R and Col 3.6-Cre; R26R mice were cultured under conditions that promote osteogenic differentiation and stained for $\beta$-gal at various times points. As early as day 5 , prior to overt colony formation, scattered stained cells were observed in both Col 2.3-Cre;R26R (Fig. 5A) and Col 3.6-Cre; R26R cultures (Fig. 5B). There were no stained cells in R26R (Cre-negative) control cultures (Fig. 5C). In Col 3.6-Cre;R26R cultures, all colonies were totally stained. However, in Col 2.3-Cre;R26R cultures, not all of the colonies were stained. Moreover, in many of the stained colonies of Col 2.3-Cre;R26R cultures, only the central cuboidal osteoblasts were stained, while the outer or inner fibroblastic cells were not (Fig. 5 D,E). In Col 3.6-Cre;R26R cultures, both the central cuboidal osteoblasts and fibroblast-like cells were stained (Fig. 5 G,H,I).

\section{Discussion}

We have generated transgenic mouse strains in which Cre has been targeted to cells of the osteoblast lineage with two different fragments of the rat Col1a1 promoter (Col2.3-Cre and Col 3.6Cre). Both transgenes were highly expressed in bone and exhibited sufficient Cre expression to cause rearrangement of the floxed ROSA26 locus in osteoblasts both in vivo and in vitro. Col 3.6-Cre was expressed early in osteoblast differentiation, whereas Col 2.3-Cre was more specific for fully differentiated osteoblasts. Thus, Col 2.3-Cre and Col 3.6-Cre transgenic mice can be used to target different populations of osteoblasts.
The calvarial suture is a fibrous joint that composed of a strip of mesenchyme that separates the proliferating edges of two dermal bones (Jiang et al., 2002). The suture allows for continuous growth during embryonic and postnatal life by providing a supply of osteoblast progenitors (Chen et al., 1998). We showed strong LacZ staining in parietal bone but not in the mesenchyme of the sagittal suture of Col 2.3-Cre;R26R calvaria. Interestingly, suture mesenchyme is derived from neural crest, while parietal bone is mesodermal origin (Jiang et al., 2002). It is possible that the distinct staining patterns were due to the different cell origins. However, both parietal (mesodermal origin) and frontal calvarial (neural crest origin) bone showed positive LacZ staining in Col 2.3-Cre;R26R and Col 3.6-Cre;R26R (data not shown). Thus, it is more likely that cell type rather than cell origin defines the difference in Col 2.3 promoter activity. In the inner periosteal layer of calvaria and long bones, cells adjacent to osteoblasts are primarily osteoprogenitor cells, while in the outer perioteal layer surrounded by an outer fibrous layer, the cells are non-osteogenic (Ross et al., 2003). The absence of staining in the outer fibrous layer of both calvariae and long bones in Col 2.3-Cre;R26R mice confirmed the more restricted expression pattern and activity of Col 2.3-Cre. Promoter strength and specificity are important considerations when designing Cre transgenes. In a recent study, a $2.3 \mathrm{~kb}$ mouse Col1a1 promoter directed Cre recombinase specifically in osteoblasts (Dacquin et al., 2002). The $2.3 \mathrm{~kb}$ mouse Col1a1 promoter is similar to the rat $2.3 \mathrm{~kb}$ fragment used in current study (Pavlin et al., 1992, Bogdanovic et al., 1994, Rossert et al., 1995, Dodig et al., 1996). In the same study, it was shown that a $1.7 \mathrm{~kb}$ murine osteocalcin gene 2 (OG2) promoter did not direct sufficient Cre expression to induce gene rearrangement in osteoblasts. However, Cre expression driven by an artificial OG2 promoter was expressed in bone and cartilage and was strong enough to cause rearrangement of the ROSA26 locus in articular chondrocytes but not in osteoblasts (Dacquin et al., 2002). Cre recombinase driven by a $3.5 \mathrm{~kb}$ human osteocalcin promoter has been used successfully to inactive expression of the IGF-I receptor in mature osteoblasts (Zhang et al., 2002). Because the osteocalcin promoter is activated late in fetal life (Frenkel et al., 1997, Quarles et al., 1997), it is not suitable for inactivating a gene during early development.

Although it is known that articular cartilage can express type I collagen (Nakamura et al., 1997, Fukunaga et al., 2003), the activity of the Col 2.3 and Col 3.6 promoters in chondrocytes has not been previously reported. In the present study, we showed that the Col 2.3 and Col 3.6 promoter were both activated in articular cartilage but only sporadically for Col 2.3. Surprisingly, we also observed the occasional activation of both Col 2.3 and Col 3.6 promoter in growth plate chondrocytes. While there is conflicting literature about whether or not type I collagen is expressed in human growth plate chondrocytes (Horton et al., 1983, Mundlos et al., 1990, Kirsch and von der Mark 1992), it is thought that type I collagen is not expressed in rat and mouse growth plate chondrocytes (Yamasaki et al., 2001, Fukunaga et al., 2003). Because LacZ staining represents a historical marking of the cells, our results suggest that $\mathrm{Col} 2.3$ and $\mathrm{Col} 3.6$ promoter might be at least transiently active in some growth plate chondrocytes before embryonic day 18.

Cre-mediated recombination provides a historical, irreversible marking of cells. It can provide unique information about the 
historical record of promoter activity. In the present study, we compared Col 2.3-GFP and Col 3.6-GFP transgene activity with the Cre-mediated recombination. With both upstream promoters, the spatial pattern of GFP expression in bone was similar but not identical to the recombination pattern observed with the respective Col-Cre transgenes. We detected Col 2.3 and Col 3.6 promoter activity in sporadic chondrocytes and articular cartilage by $\beta$-gal staining but not by GFP. In vitroculture of bone marrow cells showed that as early as day 5 , prior to colony formation, scattered $\beta$-gal expressing cells were observed in both Col 2.3-Cre;R26R and Col 3.6-Cre; R26R cultures. Interestingly, previous studies indicated that the Col 2.3-GFP transgene is activated later in osteoblast cultures derived from Col 2.3-GFP mice (Kalajzic et al., 2002). There are two possible explanations for above discrepancies. First, $\beta$-gal staining serves as a historical marker of Cre activity. Once Cre is expressed at or above a threshold level, gene rearrangement will occur and Laz expression will be permanent regardless of whether Col1a1 promoter activity persists. By contrast, a reporter such as GFP reflects the expression level of the Col 2.3 and Col 3.6 promoters in real time. Another possibility is that GFP fluorescence may not be as sensitive as $\beta$-gal staining. It is possible that weak GFP reporter expression may not have been detected; however, a very low level of Cre expression could have been sufficient to achieve gene rearrangement. Alternatively, there may be subtle differences in the expression patterns of the Cre and GFP reporters because the Col-Cre transgenes do not contain introns whereas Col-GFP transgenes have the Col1a1 first intron.

In addition to bone, it is important to note that $\beta$-gal staining was observed in non-osseous tissues of Col 2.3-Cre;R26R and Col 3.6-Cre;R26 mice including kidney, liver, skin, testes and ovaries (data not shown), consistent with very low level Cre mRNA signals in Northern blots. Therefore, when performing conditional knockouts in bone with Col-Cre transgenes, the tissue expression pattern of the gene of interest must be considered. In addition to the limitations inherent in promoter specificity, there are other potential drawbacks of the Cre/LoxP system. First, Col-Cre transgenes are constitutively active. Once there is sufficient Cre expression, rearrangement of a floxed locus will occur permanently and irreversibly, making it difficult to study gene function in a particular development stage. To obtain temporal control of gene rearrangement in osteoblasts, we are presently developing an inducible Col-Cre expression system (Nagy 2000). Second, Cre-mediated gene recombination in the male and female germ line could lead to ubiquitous gene ablation. Indeed, we have observed that ColCre mediated gene rearrangement can occur in the female and male germ line. One mechanism appears to be the transmission of Cre mRNA or protein in oocytes and sperm irrespective of inheritance of the Cre transgene (R. Cochrane, S. Clark and B. Kream, unpublished). This occurs more frequently with females than with males. Likewise, transmission of Cre protein irrespective of the Cre transgene has previously been observed when Cre was driven with a hybrid CMV-actin promoter (Sakai and Miyazaki 1997). Thus, we suggest that Col-Cre transgenes should be transmitted through the male breeder and that genotyping should be done to identify animals that display gene rearrangement in the absence of inheritance of the Cre transgene.

\section{Materials and Methods}

\section{Cloning of Col 2.3-Cre and Col 3.6-Cre expression plasmids}

Col2.3- $\Delta$ TK-ClaPa plasmid containing the rat Col1a 1 gene from -2295 to +115 bp (Visnjic et al., 2001) served as the starting vector. Cre cDNA was derived from pBS185 (Invitrogen Corporation, Carlsbad, CA, USA) using Xhol and Mlul restriction sites. In the plasmid Col 2.3- $\Delta$ TK-ClaPa, $\Delta$ TK was replaced with an Xhol-Mlul adapter using two BamHI restriction sites (Col2.3-Xhol-Mlul-ClaPa) to accept the purified Cre cDNA insert. Col 2.3Xhol-Mlul-ClaPa was cloned into pBCSK+/- (Stratagene, La Jolla, CA, USA) using Clal restriction sites. Cre cDNA was inserted into the Xhol-Mlul adapter of Col 2.3-Xhol-Mlul-ClaPa to produce Col 2.3-Cre (Fig. 1). The Col 3.6-Cre expression plasmid was obtained by cloning a $1.2 \mathrm{~kb}$ Hindlll fragment from the rat Col1a 1 promoter (bp -3518 to-2296) into Col 2.3-Cre directly upstream of bp -2295 (Fig. 1).

\section{Transgenic mice}

Transgenic mice in the outbred CD-1 background were produced in the University of Connecticut Health Center Transgenic Animal Facility by embryo microinjection of purified Col 2.3-Cre or Col 3.6Cre cDNA. The presence of the transgene in the offspring was tested by PCR analysis. The Cre indicator strain Gtrosa26 ${ }^{\mathrm{m} 1 S o r}$ (R26R) (Soriano 1999) was obtained from the Jackson Laboratory (Bar Harbor, ME, USA). Heterozygous R26R mice were bred with hemizygous Col 2.3-Cre or Col 3.6-Cre to generate experimental animals. The Institutional Animal Care and Use Committee at the University of Connecticut Health Center approved all animal protocols used in the studies.

\section{PCR Genotyping}

PCR was performed on tail DNA extracted with the Wizard Genomic DNA Purification Kit according to the manufacturer's protocol (Promega Corporation, Madison, WI). To detect the Cre transgene, PCR was performed with primers 5'-GAGTGATGAGGTTCGCAAGA-3' and 3'CTACACCAGAGACGGAAATC-5', which amplify a 615 bp fragment. Thirty cycles were performed: $94^{\circ} \mathrm{C}, 30 \mathrm{~s} ; 65^{\circ} \mathrm{C}, 30 \mathrm{~s} ; 72^{\circ} \mathrm{C}, 2 \mathrm{~min}$. To detect the engineered ROSA26 locus, PCR was performed as described previously (Soriano 1999).

\section{RNA extraction and Northern blot analysis}

Total RNA was extracted from various tissues using TRIzol reagent (Invitrogen Corporation, Carlsbad, CA, USA) according to manufacture's protocol. $10 \mu \mathrm{g}$ of RNA were analyzed by Northern blotting as described previously (Woitge and Kream 2000).

\section{Histochemical detection of $\beta$-gal activity}

Histochemical detection of $\beta$-gal activity was performed in bone marrow stromal cells; in calvaria, femur, tibiae and feet from embryonic day 18 (E18) and postnatal day 5 (P5) animals. Tissues were dissected in PBS and fixed for $3 \mathrm{~h}$ in a $0.1 \mathrm{M}$ sodium phosphate buffer $(\mathrm{pH} 7.3$ ) containing $0.2 \%$ gluteraldehyde, $5 \mathrm{mM}$ EGTA and $2 \mathrm{mM}$ magnesium chloride. Following 3 wash cycles with a buffer containing $0.1 \mathrm{M}$ sodium phosphate buffer $(\mathrm{pH}$ 7.3), $2 \mathrm{mM}$ magnesium chloride, $0.01 \%$ deoxycholate and $0.02 \%$ Nonidet$\mathrm{P} 40$, tissues were incubated for $4 \mathrm{~h}$ at $37^{\circ} \mathrm{C}$ with X-gal staining solution containing $50 \mathrm{mg}$ X-gal (Sigma Chemical Company, St. Louis, MO, USA), $0.106 \mathrm{~g}$ potassium ferrocyanide and $0.082 \mathrm{~g}$ potassium ferricyanide in 50 $\mathrm{ml}$ wash buffer. Cells were fixed in phosphate buffer, $\mathrm{pH} 7.3$, containing $0.2 \%$ gluteraldehyde for $5 \mathrm{~min}$, rinsed 3 times with phosphate buffer and stained for $16 \mathrm{~h}$ at $37^{\circ} \mathrm{C}$. After staining, tissues were washed 3 times, placed overnight in fixative containing $10 \%$ formalin, decalcified and embedded in paraffin. Six- $\mu \mathrm{m}$ thick sections were counterstained with hematoxylin.

\section{Histological evaluation of GFP expression}

Calvaria and hind limbs were dissected from hemizygous pOBCol3.6GFPtpz and pOBCol2.3-GFPemd (Kalajzic et al., 2002) E18 and P5 transgenic mice. Tissue fragments were fixed in $4 \%$ paraformaldehyde/ 
PBS, decalcified in 15\% EDTA, processed and embedded in paraffin using standard protocols. Serial sections of 6- to $7 \mu \mathrm{m}$ thick were placed onto ProbeOn Plus slides (Fisher Scientific, Pittsburgh, PA, USA). GFP was visualized as described previously (Braut et al., 2003).

\section{Bone marrow stromal cell cultures}

Femurs and tibias from 6- to 8-week-old mice were dissected from surrounding tissues. The epiphyseal growth plates were removed and the marrow was collected by flushing with $\alpha$-modified essential medium $(\alpha-$ MEM) containing $100 \mathrm{U} / \mathrm{ml}$ penicillin, $100 \mu \mathrm{g} / \mathrm{ml}$ of streptomycin and $10 \%$ fetal calf serum (FCS) with a 25-gauge needle. Single cell suspensions were prepared by passing the cell clumps through an 18-gauge needle followed by filtration through a $70 \mu \mathrm{m}$ cell strainer (Fisher Scientific). Cells were plated at a density of $2-2.5 \times 10^{6} \mathrm{cells} / \mathrm{cm}^{2}$ in $35 \mathrm{~mm}$ Falcon culture plates (Fisher Scientific, Pittsburgh, PA, USA). On day 4, half of the medium (containing non-adherent cells) was replaced with fresh medium. Medium was changed completely on day 7 to a-MEM supplemented with $50 \mathrm{mg} / \mathrm{ml}$ ascorbic acid and $8 \mathrm{mM} \beta$-glycerophosphate (Sigma Chemical Company, St. Louis, MO, USA). Medium was changed every 2 days for the duration of the experiment.

\section{Acknowledgements}

This work was supported by grant P01 AR38933 to BEK from the National Institute of Arthritis and Musculoskeletal and Skin Diseases (NIAMS) and by grant DE13363 to MM from the National Institute of Dental and Craniofacial Research (NIDCR). HWW received support from the Deutsche Forschungsgemeinschaft grant Wo 729/1-1.

\section{References}

BOGDANOVIC, Z., A. BEDALOV, P. H. KREBSBACH, D. PAVLIN, C. O. WOODY, S. H. CLARK, H. F. THOMAS, D. W. ROWE, B. E. KREAM and A. C. LICHTLER. (1994). Upstream regulatory elements necessary for expression of the rat COL1A1 promoter in transgenic mice. J Bone Miner Res 9: 285-292.

BRAUT, A., E. J. KOLLAR and M. MINA. (2003). Analysis of the odontogenic and osteogenic potentials of dental pulp in vivo using a col1a1-2.3-GFP transgene. Int $J$ Dev Bio/47: 281-292.

CHEN, H., D. OVCHINNIKOV, C. L. PRESSMAN, A. AULEHLA, Y. LUN and R. L. JOHNSON. (1998). Multiple calvarial defects in Imx1b mutant mice. Dev Genet22: 314-320.

DACQUIN, R., M. STARBUCK, T. SCHINKE and G. KARSENTY. (2002). Mouse alpha1(I)-collagen promoter is the best known promoter to drive efficient Cre recombinase expression in osteoblast. Dev Dyn224: 245-251.

DODIG, M., M. S. KRONENBERG, A. BEDALOV, B. E. KREAM, G. GRONOWICZ, S. H. CLARK, K. MACK, Y. H. LIU, R. MAXON, Z. Z. PAN, W. B. UPHOLT, D. W. ROWE and A. C. LICHTLER. (1996). Identification of a TAAT-containing motif required for high level expression of the COL1A1 promoter in differentiated osteoblasts of transgenic mice. J Biol Chem 271: 16422-16429.

DUCY, P., V. GEOFFROY and G. KARSENTY. (1996). Study of osteoblast-specific expression of one mouse osteocalcin gene: characterization of the factor binding to OSE2. Connect Tissue Res 35: 7-14.

FRENKEL, B., C. CAPPARELLI, M. VAN AUKEN, D. BARAN, J. BRYAN, J. L. STEIN, G. S. STEIN and J. B. LIAN. (1997). Activity of the osteocalcin promoter in skeletal sites of transgenic mice and during osteoblast differentiation in bone marrowderived stromal cell cultures: effects of age and sex. Endocrinology 138: 21092116.

FUKUNAGA, T., T. YAMASHIRO, S. OYA, N. TAKESHITA, M. TAKIGAWA and T. TAKANO-YAMAMOTO. (2003). Connective tissue growth factor mRNA expression pattern in cartilages is associated with their type I collagen expression. Bone 33: 911-918.

GUO, H., C. MAO, X. L. JIN, H. WANG, Y. T. TU, P. P. AVASTHI and Y. LI. (2000). Cre-mediated cerebellum- and hippocampus-restricted gene mutation in mouse brain. Biochem Biophys Res Commun 269: 149-154.

HOFFMANN, H. M., T. L. BEUMER, S. RAHMAN, L. R. MCCABE, C. BANERJEE, F. ASLAM, J. A. TIRO, A. J. VAN WIJNEN, J. L. STEIN, G. S. STEIN and J. B. LIAN.
(1996). Bone tissue-specific transcription of the osteocalcin gene: role of an activator osteoblast-specific complex and suppressor hox proteins that bind the OC box. J Cell Biochem 61: 310-324.

HORTON, W. A., C. DWYER, R. GOERING and D. C. DEAN. (1983). Immunohistochemistry of types I and II collagen in undecalcified skeletal tissues. JHistochem Cytochem 31: 417-425.

JIANG, X., S. ISEKI, R. E. MAXSON, H. M. SUCOV and G. M. MORRISS-KAY. (2002). Tissue origins and interactions in the mammalian skull vault. Dev Bio/241: 106-116.

KALAJZIC, I., Z. KALAJZIC, M. KALITERNA, G. GRONOWICZ, S. H. CLARK, A. C. LICHTLER and D. ROWE. (2002). Use of type I collagen green fluorescent protein transgenes to identify subpopulations of cells at different stages of the osteoblast lineage. J Bone Miner Res 17: 15-25.

KARAPLIS, A. C. and H. M. KRONENBERG. (1996). Physiological roles for parathyroid hormone-related protein: lessons from gene knockout mice. Vitam Horm52: 177-193.

KIRSCH, T. and K. VON DER MARK. (1992). Remodelling of collagen types I, II and $X$ and calcification of human fetal cartilage. Bone Miner 18: 107-117.

KULKARNI, R. N., J. C. BRUNING, J. N. WINNAY, C. POSTIC, M. A. MAGNUSON and C. R. KAHN. (1999). Tissue-specific knockout of the insulin receptor in pancreatic beta cells creates an insulin secretory defect similar to that in type 2 diabetes. Cel/96: 329-339.

LI, H., J. WANG, H. WILHELMSSON, A. HANSSON, P. THOREN, J. DUFFY, P. RUSTIN and N. G. LARSSON. (2000). Genetic modification of survival in tissuespecific knockout mice with mitochondrial cardiomyopathy. Proc Nat/ Acad Sci USA 97: 3467-3472.

LIU, J. L., S. YAKAR and D. LEROITH. (2000). Conditional knockout of mouse insulinlike growth factor-1 gene using the Cre/loxP system. Proc Soc Exp BiolMed223: 344-351.

MUNDLOS, S., H. ENGEL, I. MICHEL-BEHNKE and B. ZABEL. (1990). Distribution of type I and type II collagen gene expression during the development of human long bones. Bone 11: 275-279.

NAGY, A. (2000). Cre recombinase: the universal reagent for genome tailoring. Genesis 26: 99-109.

NAKAMURA, M., J. WATANABE, R. OGAWA and S. KANAMURA. (1997). Immunohistochemical localization of type II and type I collagens in articular cartilage of the femoral head of dexamethasone-treated rats. Histochem J29: 645-654.

PAVLIN, D., A. C. LICHTLER, A. BEDALOV, B. E. KREAM, J. R. HARRISON, H. F. THOMAS, G. A. GRONOWICZ, S. H. CLARK, C. O. WOODY and D. W. ROWE. (1992). Differential utilization of regulatory domains within the alpha 1(I) collagen promoter in osseous and fibroblastic cells. J Cell Bio/116: 227-236.

QUARLES, L. D., S. R. SIDDHANTI and S. MEDDA. (1997). Developmental regulation of osteocalcin expression in MC3T3-E1 osteoblasts: minimal role of the proximal E-box cis-acting promoter elements. J Cell Biochem 65: 11-24.

ROSS, M. H., KAYE G. I., PAWLINA, W. (2003). Histology (a text and atlas) (Ed. B. Cady). $4^{\text {th }}$ Edition. Lippincott Williams \& Wilkins, Baltimore (MD). pp. 181-197.

ROSSERT, J., H. EBERSPAECHER and B. DE CROMBRUGGHE. (1995). Separate cis-acting DNA elements of the mouse pro-alpha 1(I) collagen promoter direct expression of reporter genes to different type I collagen-producing cells in transgenic mice. J Cel/ Bio/129: 1421-1432.

SAKAI, K. and J. MIYAZAKI. (1997). A transgenic mouse line that retains Cre recombinase activity in mature oocytes irrespective of the cre transgene transmission. Biochem Biophys Res Commun 237: 318-324.

SAUER, B. (1993). Manipulation of transgenes by site-specific recombination: use of Cre recombinase. Methods Enzymo/225: 890-900.

SAUER, B. and N. HENDERSON. (1988). Site-specific DNA recombination in mammalian cells by the Cre recombinase of bacteriophage P1. Proc Nat/Acad Sci USA 85: 5166-5170.

SJOGREN, K., J. L. LIU, K. BLAD, S. SKRTIC, O. VIDAL, V. WALLENIUS, D. LEROITH, J. TORNELL, O. G. ISAKSSON, J. O. JANSSON and C. OHLSSON. (1999). Liver-derived insulin-like growth factor I (IGF-I) is the principal source of IGF-I in blood but is not required for postnatal body growth in mice. ProcNat/Acad Sci USA 96: 7088-7092.

SORIANO, P. (1999). Generalized lacZ expression with the ROSA26 Cre reporter strain. Nat Genet 21: 70-71. 
TRONCHE, F., C. KELLENDONK, O. KRETZ, P. GASS, K. ANLAG, P. C. ORBAN, R. BOCK, R. KLEIN and G. SCHUTZ. (1999). Disruption of the glucocorticoid receptor gene in the nervous system results in reduced anxiety. Nat Genet23: 99-103.

VISNJIC, D., I. KALAJZIC, G. GRONOWICZ, H. L. AGUILA, S. H. CLARK, A. C. LICHTLER and D. W. ROWE. (2001). Conditional ablation of the osteoblast lineage in Col 2.3deltatk transgenic mice. J Bone Miner Res 16: 2222-2231.

WOITGE, H. W. and B. E. KREAM. (2000). Calvariae from fetal mice with a disrupted Igf1 gene have reduced rates of collagen synthesis but maintain responsiveness to glucocorticoids. J Bone Miner Res 15: 1956-1964.

YAKAR, S., J. L. LIU, B. STANNARD, A. BUTLER, D. ACCILI, B. SAUER and D. LEROITH. (1999). Normal growth and development in the absence of hepatic insulin-like growth factor I. Proc Nat/ Acad Sci USA 96: 7324-7329.
YAMASAKI, A., M. ITABASHI, Y. SAKAI, H. ITO, Y. ISHIWARI, H. NAGATSUKA and N. NAGAI. (2001). Expression of type I, type II and type $X$ collagen genes during altered endochondral ossification in the femoral epiphysis of osteosclerotic (oc/oc) mice. Calcif Tissue Int 68: 53-60.

ZHANG, M., S. XUAN, M. L. BOUXSEIN, D. VON STECHOW, N. AKENO, M. C. FAUGERE, H. MALLUCHE, G. ZHAO, C. J. ROSEN, A. EFSTRATIADIS and T. L. CLEMENS. (2002). Osteoblast-specific knockout of the insulin-like growth factor (IGF) receptor gene reveals an essential role of IGF signaling in bone matrix mineralization. J Biol Chem 277: 44005-44012.

Received: March 2004

Reviewed by Referees: April 2004

Modified by Authors and Accepted for Publication: May 2004 